\title{
INDICADORES DA PRODUÇÃO CIENTÍFICA E CO-AUTORIA: ANÁLISE DO DEPARTAMENTO DE CIÊNCIAS DA INFORMAÇÃO DA UFRGS
}

\author{
Josiane Gonçalves da Costa ${ }^{\mathrm{i}}$ \\ Samile Andrea de Souza Vanz
}

\begin{abstract}
Resumo: Através da Bibliometria, investigam-se as características de 248 documentos publicados pelos docentes do Departamento de Ciências da Informação da Universidade Federal do Rio Grande do Sul entre 2000 e 2008. O objetivo do estudo foi delinear o perfil de publicação departamental em relação aos seguintes indicadores: tipologia dos documentos, assunto, idioma, ano e local de publicação, redes de colaboração, títulos de periódicos e eventos utilizados como canais de comunicação científica. Os resultados indicam uma tendência à pesquisa colaborativa entre os docentes investigados, seus colegas e alunos da faculdade $(74,3 \%)$, e revelam que anais de eventos e periódicos nacionais são os canais mais utilizados pelos professores para comunicação científica. Destaca como eventos mais utilizados para publicação o CBBD e INTERCOM e aponta a revista Em Questão (publicação eletrônica da faculdade) como principal periódico. Reforça a ideia de que a Ciência da Informação no Brasil ainda é um campo em formação, sem padrões próprios de comportamento em relação à comunicação científica. Conclui que a Bibliometria é um método eficiente para coleta de subsídios à tomada de decisões no âmbito das políticas cientificas e da gestão de bibliotecas, mas requer atenção quanto à interpretação dos resultados.
\end{abstract}

Palavras-chave: Bibliometria. Cientometria. Produção científica. Colaboração científica. Co-autoria. Ciência da Informação. UFRGS.

\section{SCIENTIFIC PRODUCTION'S INDICATORS AND CO-AUTHORSHIP: ANALYSIS OF INFORMATION SCIENCE DEPARTMENT AT UFRGS}

\begin{abstract}
This bibliometric study investigates the characteristics of teachers's scientific production (PI) on DCI/UFRGS, published and recorded in SABi between 2000 and 2008 with the aim of study the publication's profile using the indicators: Document Type, Publication Year, Country, Co-authors, Subjects, Proceedings and Journals used as a channel of scientific communication. It's reveals a tendency to collaborative research between teachers and FABICO's students and teachers (74.3\%). Brazillian proceedings and periodicals are the most important channels of scientific communication. The most important events were: CBBD and INTERCOM. The journal Em Questão (FABICO's electronic journal) was often used and as a channel of scientific communication. Information Science is still a field in training in Brazil, without standards of scientific communication's behavior. Bibliometrics is an efficient method to collect subsidies for science decision making, but it requires attention as results's interpretation.
\end{abstract}

Key-words: Bibliometrics. Scientometrics. Scientific Production. Scientific Collaboration. Co-authorship. Information Science. UFRGS.

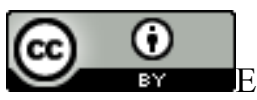

Esta obra está licenciada sob uma Licença Creative Commons

\footnotetext{
${ }^{\mathrm{i}}$ Universidade Federal do Rio Grande do Sul. costa.josian@gmail.com.

${ }^{\text {ii } U n i v e r s i d a d e ~ F e d e r a l ~ d o ~ R i o ~ G r a n d e ~ d o ~ S u l . ~ s a m i l e v a n z @ t e r r a . c o m . b r . ~}$

Recebido em: 14/06/2011, aceito para publicação em: 22/01/2012.
} 


\section{INTRODUÇÃO}

Segundo Meadows (1999), a comunicação científica é tão vital para o desenvolvimento da Ciência quanto a própria pesquisa, pois a legitimação dos resultados de uma investigação depende da avaliação dos pares e divulgação dentro da comunidade científica. Por esta razão, a pesquisa envolve várias atividades de comunicação e deveria produzir pelo menos uma publicação formal. O conjunto de publicações resultantes do processo de desenvolvimento do saber em uma determinada área do conhecimento denominase literatura científica ou especializada.

O corpus da literatura científica, técnica, artística e administrativa produzida no circuito da Universidade Federal do Rio Grande do Sul (UFRGS) por seu quadro de professores, servidores técnico-administrativo e alunos (quando orientados por docente vinculado à universidade) denomina-se Produção Intelectual. A organização destes documentos pelo Sistema de Bibliotecas da UFRGS (SBU) visa à preservação da memória institucional, garante a divulgação e facilita o acesso. Por esta razão, estudos sobre a produção intelectual no âmbito acadêmico são úteis para o estabelecimento de políticas e decisões por parte de governos, órgãos financiadores e da própria instituição. Um dos exemplos destas ações estratégicas é o uso da produção intelectual registrada pelas bibliotecas como um dos quesitos para o cálculo dos valores atribuídos aos departamentos, de acordo com a Decisão n ${ }^{\circ}$ 118/2001 do Conselho Universitário (CONSUN), de 17 de agosto de 2001, que institui o Banco de Vagas Docentes da UFRGS e as normas para a destinação dessas vagas.

A identificação das características da produção científica na área da Ciência da Informação não só auxilia no conhecimento sobre esta área no Brasil, como também pode apoiar decisões estratégicas no âmbito departamental, reduzindo o nível de incerteza na gestão de sistemas de informação, já que estes indicadores refletem, ainda que com ressalvas, a realidade dos hábitos de publicação docente e permitem que sejam testadas hipóteses sobre o comportamento social deste grupo. O estudo dos aspectos quantitativos da produção, disseminação e utilização das informações registradas que permite desenvolver modelos matemáticos e medidas para estes processos e utilizá-los posteriormente como subsídios para tomada de decisão denomina-se Bibliometria (TAGUE-SUTCLIFFE, 1992, p. 1, tradução nossa).

Inicialmente, o viés da Bibliometria era a estatística bibliográfica (edições, exemplares, número de palavras, dimensão dos livros, etc.). Com o tempo, a técnica dirigiu-se 
para estudos de outros tipos de documentos, como artigos de periódicos e mais recentemente, avança para investigações sobre produtividade de autores e análise de citações (ARAÚJO, 2006). Conforme Sengupta (1992, p. 83, tradução nossa), os estudos bibliométricos podem ser aplicados para identificar linhas de pesquisa; prever a produtividade de autores, editores, organizações, países ou de uma área como um todo; iniciar sistemas efetivos de redes sociais; regular os fluxos informacionais e comunicativos; desenvolver normas de padronização; etc. Os resultados destes estudos podem interferir no âmbito da gestão acadêmica, quando é preciso obter indicadores para definir o nível de produtividade dos autores científicos, a visibilidade de seus trabalhos e as relações de co-autoria (VANZ; CAREGNATO, 2003; VANTI, 2002).

O Departamento de Ciências da Informação (DCI), de acordo com Santos (2000), originou-se em 1999, a partir do Departamento de Biblioteconomia e Documentação da UFRGS, o qual surgiu em 1970, no ato da criação da Faculdade de Biblioteconomia e Comunicação (FABICO). Desde o surgimento até os dias atuais, reflexões sobre a própria identidade são rotineiras no DCI, refletindo as características da própria área, uma disciplina jovem em relação a outras disciplinas, gestada no período pós-Segunda Guerra, formalizada cientificamente na recente década de 50 e marcada pela ausência de um conjunto de bases conceituais que possam delinear seu horizonte científico.

Saracevic (1996) enumera três preceitos que regem a existência e evolução desta área: a interdisciplinaridade; o imperativo tecnológico que impõe as principais transformações na sociedade; e a forte dimensão social e humana da Sociedade da Informação, que transcende à tecnologia. Le Coadic (2004) corrobora o enunciado anterior afirmando que a Ciência da Informação se aproxima do amadurecimento enquanto ciência ao referir-se cada vez mais a sua própria história.

No Brasil, a Ciência da Informação teve início da década de 70 com a criação do curso de pós-graduação em nível de mestrado do Instituto Brasileiro de Informação em Ciência e Tecnologia (IBICT). Apenas vinte anos depois, criou-se o primeiro doutorado, pela Escola de Comunicação da Universidade Federal do Rio de Janeiro (ECO/UFRJ). Apesar de recente, Stumpf (2008) acredita que a área acelera seu fortalecimento através de discussões sobre suas fundamentações teóricas e metodológicas, reforçando a importância de estudos da produção do conhecimento científico em Ciência da Informação. Neste sentido, a Bibliometria auxilia os pesquisadores na medida em que se presta a avaliar quantitativamente diversos aspectos da produção científica, não dedutíveis de maneira frívola. 
Com o intuito de subsidiar o debate acerca das perspectivas para a Ciência da Informação no Brasil, este estudo bibliométrico tem como objetivo delinear o perfil das publicações do DCI através da investigação de um conjunto formado por todos os 248 documentos publicados entre 2000 e 2008 por 24 professores permanentes vinculados ao DCI/UFRGS, em relação aos seguintes indicadores: tipologia dos documentos publicados, local e ano de publicação, idioma, assunto, títulos de periódicos e eventos utilizados como canais de comunicação científica e redes de colaboração. Nas seções que seguem, apresentase a metodologia empregada e os resultados encontrados, além de algumas considerações sobre as contribuições da Bibliometria para a Ciência da Informação.

\section{PROCEDIMENTOS METODOLÓGICOS}

O corpus de análise deste estudo compreende todos os 248 documentos publicados por 24 docentes do corpo permanente do DCI no período de 2000 a 2008, registrados no Sistema de Automação de Bibliotecas (SABi) até 01 de agosto de 2009. Para constituir esta população foram elencadas as publicações no formato de livros, capítulos de livros, artigos de periódicos (nacionais, estrangeiros, indexados e não indexados) e eventos. Documentos manuscritos (teses, dissertações, relatórios técnicos, relatórios de pesquisa e projetos de pesquisa) e documentos sem referências (publicados sob a forma de resumos) foram excluídos. Suprimiuse também a produção intelectual em que o docente participa como orientador, organizador, colaborador, tradutor, editor, etc., pois se considera que o autor é a pessoa ou entidade que possui a responsabilidade principal na criação do conteúdo intelectual ou artístico de uma obra (SPINAK, 1996, p. 27).

Os 248 documentos tiveram seus dados compilados manualmente para uma planilha eletrônica desenvolvida no programa Microsoft Excel versão 2007. A organização das planilhas aconteceu de forma a possibilitar a análise dos documentos em relação aos seguintes indicadores: tipologia dos documentos publicados, idioma, local e ano de publicação, assunto, títulos de periódicos e eventos utilizados como canais de comunicação científica e redes de colaboração. As considerações obtidas a partir dos dados extraídos da planilha foram apresentadas textualmente e na forma de gráficos, grafo e tabelas, geradas a partir dos programas Microsoft Excel e UCINET 6 for Windows. 


\section{RESULTADOS}

Conforme Souza e Stumpf (2009), investigar as peculiaridades da Ciência da Informação é essencial para seu desenvolvimento, pois essa área é marcada por características únicas por ser uma área de desenvolvimento recente e por congregar professores, pesquisadores e profissionais com diferentes formações acadêmicas e atuações diversificadas.

Os resultados obtidos neste estudo e apresentados a seguir representam fatos circunstanciais no espaço e no tempo, mas revelam facetas importantes da produção intelectual docente no DCI e conseqüentemente, podem refletir também a área da Ciência da Informação. A frequência com que os diversos tipos de documentos foram utilizados pelos docentes como veículos de divulgação da produção intelectual se apresenta na tabela 1 .

\begin{tabular}{c|lcc}
\hline & \multicolumn{1}{|c}{ Tipo de Documento } & Freq. PI & \% de PI \\
\hline \multirow{2}{*}{ Eventos } & Trabalho Evento Nacional & 104 & 41,9 \\
& Trabalho Evento Internacional & 10 & 4,0 \\
& Total & $\mathbf{1 1 4}$ & $\mathbf{4 6 , 0}$ \\
\hline \multirow{2}{*}{ Periódicos } & Artigo Nacional Indexado & 75 & 30,2 \\
& Artigo Nacional não Indexado & 19 & 7,7 \\
& Artigo Internacional Indexado & 2 & 0,8 \\
& Artigo Internacional não Indexado & 3 & 1,2 \\
& Total & $\mathbf{9 9}$ & $\mathbf{3 9 , 9}$ \\
\hline \multirow{2}{*}{ Livros } & Capítulo de Livro & 31 & 12,5 \\
& Livro & 4 & 1,6 \\
& Total & $\mathbf{3 5}$ & $\mathbf{1 4 , 1}$ \\
\hline & Total geral & $\mathbf{2 4 8}$ & $\mathbf{1 0 0 , 0}$ \\
\hline
\end{tabular}

Tabela 1: Tipologia dos documentos usados para publicação da produção intelectual.

Fonte: dados da pesquisa

Os diversos tipos de veículos utilizados para publicação da produção intelectual refletem o interesse e/ou a necessidade dos docentes em dar visibilidade aos seus trabalhos, e talvez por isso, a maior publicação de artigos em periódicos e eventos consolidados nacionalmente, porque estes veículos se caracterizam pela rapidez e controle - quando comparado a publicação em livro. Os periódicos por sua vez conseguem maior alcance de público do que outros veículos.

O livro, apesar de ser considerado um controverso canal de comunicação científica devido ao alto custo de produção e também aos longos prazos para edição que podem contribuir para desatualizar a informação, ainda concentra a preferência de muitos pesquisadores das humanidades (MEADOWS, 1999). A preferência pela publicação em livro nas Ciências Humanas, Ciências Sociais Aplicadas e Lingüística, Letras e Artes já foi demonstrada em estudos de Muller (2005). No Departamento de Ciências da Informação da 
UFRGS (DCI/UFRGS), 35 trabalhos foram publicados como livro ou capítulo, perfazendo $14,1 \%$ da preferência dos docentes.

$\mathrm{Na}$ análise de referências citadas nos trabalhos publicados pelos professores do DCI/UFRGS entre 2000 e 2008, Costa e Vanz (2010) verificaram um percentual de 44,0\% para citações de livros e capítulos, sinalizando a preferência dos professores da área de Ciência da Informação por fontes de conhecimento já consolidadas. Em segundo lugar, figura o artigo de periódico $(31,3 \%)$.

Em relação ao idioma da Produção Intelectual, observou-se uma forte tendência à publicação em português (96\%). O percentual elevado para o idioma vernáculo já era esperado, pois foi constatado anteriormente que os veículos mais utilizados para divulgação das publicações foram eventos e periódicos nacionais. Seguindo a lógica, o Brasil figura como país de publicação predominante com $94,0 \%$. Este resultado revela que os professores do DCI não têm transito em eventos internacionais e tampouco o hábito de publicar em periódicos fora do Brasil, o que pode indicar o isolamento científico do departamento.

O exame do ano de publicação dos documentos revelou que o DCI possui uma média de publicação anual de 27,5 trabalhos. Entretanto, ao comparar esta média com as frequências apresentadas na Tabela 2, percebe-se que o número de publicações oscila bastante de ano para ano.

Verificou-se também que nos anos de 2001, 2002 e 2008, o número de publicações está inferior aos demais anos. Esses dados interessam à coordenação do departamento e à própria Universidade, pois viabiliza o estabelecimento de políticas e incentivos à publicação, além de ações anteriores à publicação, como o financiamento a projetos de pesquisa, alocação de bolsas de pesquisa a docentes e alunos entre outras ações que fomentam a atividade científica.

\begin{tabular}{l|cccccccccc}
\hline \multirow{1}{*}{\multicolumn{1}{c|}{ Tipo de Documento }} & \multicolumn{10}{c}{ Freq. PI } \\
\cline { 2 - 11 } & 2000 & 2001 & 2002 & 2003 & 2004 & 2005 & 2006 & 2007 & 2008 \\
\hline Trabalho Evento Nacional & 11 & 1 & 7 & 12 & 11 & 20 & 12 & 17 & 13 \\
Capítulo de Livro & 3 & 4 & 1 & 2 & 4 & 5 & 2 & 9 & 1 \\
Artigo Nacional Indexado & 16 & 0 & 2 & 12 & 12 & 6 & 14 & 8 & 5 \\
Artigo Nacional não Indexado & 0 & 0 & 2 & 6 & 2 & 2 & 4 & 1 & 2 \\
Trabalho Evento Internacional & 1 & 2 & 0 & 0 & 0 & 0 & 1 & 6 & 0 \\
Livro & 0 & 2 & 0 & 0 & 0 & 0 & 0 & 1 & 1 \\
Artigo Internacional Indexado & 1 & 0 & 0 & 0 & 1 & 0 & 0 & 0 & 0 \\
Artigo Internacional não Indexado & 1 & 0 & 0 & 0 & 0 & 1 & 0 & 0 & 1 \\
\hline \multicolumn{1}{c}{ Total } & $\mathbf{3 3}$ & $\mathbf{9}$ & $\mathbf{1 2}$ & $\mathbf{3 2}$ & $\mathbf{3 0}$ & $\mathbf{3 4}$ & $\mathbf{3 3}$ & $\mathbf{4 2}$ & $\mathbf{2 3}$ \\
\hline
\end{tabular}

Tabela 2: Data de publicação da PI por tipo de documento

Fonte: dados da pesquisa 
Constatou-se pelos resultados uma preferência pela publicação de trabalhos em eventos nacionais tradicionais, promovidos pelas principais instituições das áreas de Ciência da Informação e Comunicação no Brasil, como o Congresso Brasileiro de Biblioteconomia, Documentação e Ciências da Informação (CBBD), que perfez 25,4\% da produção intelectual; o Encontro Nacional de Pesquisa em Ciência da Informação (ENANCIB), onde foram publicados 20,2\% dos trabalhos; e Congresso Brasileiro de Ciências da Comunicação (INTERCOM), com $8,8 \%$ da produção. Os resultados apontam para a natureza interdisciplinar dos trabalhos publicados pelos docentes do DCI, os quais participam de congressos tradicionais em Ciência da Informação e Comunicação, o que pode ser uma consequência da integração que acontece na Faculdade de Biblioteconomia e Comunicação (FABICO) da UFRGS. A FABICO reúne seis cursos de graduação - Biblioteconomia, Arquivologia, Museologia, Jornalismo, Relações Públicas e Publicidade e Propaganda organizados em dois departamentos, o Departamento de Ciências da Informação e o Departamento de Comunicação. Em nível de pós-graduação a integração entre as áreas é ainda mais efetiva no Programa de Pós-Graduação em Comunicação e Informação (PPGCOM).

Para tentar entender o comportamento de produção intelectual do DCI/UFRGS realizou-se uma análise de correlação entre o número total de documentos publicados anualmente e a produção por tipos de documentos utilizados como veículo de comunicação científica. Os resultados são apresentados na tabela a seguir:

\begin{tabular}{lrr}
\hline \multicolumn{1}{c}{ Variáveis relacionadas } & \multicolumn{2}{c}{ Produção intelectual total } \\
\cline { 2 - 3 } & Coeficiente de correlação & Coeficiente de determinação \\
\cline { 2 - 3 } Trabalho Evento Nacional & 0,833491176 & 0,694707541 \\
Artigo Nacional Indexado & 0,722308471 & 0,521729528 \\
Livro & $-0,431594955$ & 0,186274206 \\
\hline
\end{tabular}

Tabela 3: Correlação de Pearson entre a produção intelectual

Observa-se que a produção intelectual total apresenta coeficientes de correlação de Pearson altos quando correlacionado com Trabalho em evento nacional $(0,83)$ e Artigo nacional indexado $(0,72)$, indicando que estes tipos de documentos se correlacionam com o aumento da produção intelectual do DCI. Quando correlacionado com a produção de livros, o coeficiente é $-0,43$, indicando que ocorre uma queda de produtividade nos anos em que os docentes publicaram mais livros. No ano de 2001, por exemplo, foram publicados dois livros e quatro capítulos de livros, ao passo que o número de trabalhos publicados em eventos foi (um) e artigos de periódicos publicados foi 0 (zero). Pode-se inferir que a produção de livros 
exige mais tempo do professor para publicação do que outros tipos de documentos, como capítulos de livros, artigos de periódicos e trabalhos em evento.

Os coeficientes de determinação corroboram com a idéia, visto que 69,47\% da variação do total de publicações (considerada a variável dependente) devem-se às variações da variável Trabalho em Evento Nacional. Artigo Nacional Indexado também representa um percentual alto $(52,17 \%)$, ao passo que Livro é responsável por $18,62 \%$ das variações na produção intelectual total.

Os resultados da análise dos títulos de periódicos mais usados para publicação da PI podem ser conferidos na tabela 4. Estes resultados apontam para uma tendência à publicação em periódicos com idade superior a dez anos e editados por universidades.

Segundo Mueller e Passos (2000), o periódico científico é considerado o veículo de maior visibilidade para resultados de pesquisa. Em relação às decisões finais sobre onde publicar, Meadows (1999, p. 171) afirma que a escolha depende do exame de periódicos (ou editoras) específicos e até onde suas políticas editoriais coincidem com os anseios do autor: "Os pesquisadores que encontram um periódico satisfatório onde publicar provavelmente voltarão a submeter-lhe novas colaborações.”.

\begin{tabular}{l} 
Título do Periódico \\
\hline Em Questão: revista da faculdade de \\
biblioteconomia e comunicação da UFRGS. \\
Porto Alegre. Continuação de Revista de \\
biblioteconomia e comunicação. Porto Alegre \\
Informação \& Sociedade: estudos. João \\
pessoa \\
In Texto: revista do mestrado da comunicação \\
UFRGS. Porto alegre \\
Revista ACB: Biblioteconomia em Santa \\
Catarina \\
Revista Ciência da Informação. Brasília \\
Signos. Lajeado \\
Ecos: revista da escola de comunicação social \\
E-compós: Revista da Associação Nacional \\
dos \\
Programas de pós-graduação em \\
Comunicação. Brasília. \\
Encontros Bibli: Revista Eletrônica de
\end{tabular}

Indexado por

$\begin{array}{cccc}\text { Qual } & \text { Freq. } & \% \text { de } & \sum \% \\ \text { is } & \text { PI } & \text { PI } & \text { de PI }\end{array}$

Latindex; Doaj; Brapci

B2 36

$36,4 \quad 36,4$

Infobila; Lisa;

ISI Web of

Knowledge; $\quad$ B1 $11 \quad 11,1 \quad 47,5$

Clase;

Latindex; Doaj

$\begin{array}{lllll}\text { Latindex } & \text { B2 } & 4 & 4,0 & 51,6\end{array}$

Latindex; Doaj; Brapci

B4 $4 \quad 4,0 \quad 55,6$

Lisa; Clase;

Scopus; Scielo

A2 $4 \quad 4,0 \quad 59,6$

...

B4 $4 \quad 4,0 \quad 63,7$

$\cdots$

B3 3

Latindex

B1 2

2,0

68,7

Encontros Bibli: Revista Eletrônica de

Brapci; Doaj; $\quad$ B2 $22,0 \quad 70,7$


Biblioteconomia e Ciência da Informação

Hífen. Uruguaiana

Informática na Educação. Porto Alegre

Perspectivas em Ciência da Informação.

Belo Horizonte

Revista Digital de Biblioteconomia e Ciência

da Informação. Campinas

Revista Famecos. Porto Alegre

Transinformação. Campinas

17 periódicos usados 1 vez como veículo de comunicação científica

Laptoc;

Redalyc; EZB

$\begin{array}{lllll}\text { Acaap } & \text { B5 } & 2 & 2,0 & 72,8\end{array}$

$\begin{array}{llll}\text { Laptoc Não } & 2 & 2,0 & 74,8\end{array}$

ISI Web of

Knowledge;

Scopus; Lisa; $\quad$ A2 $22 \quad 2,0 \quad 76,8$

Scielo

E-lis;

Doaj;Brapci

Ebsco; Ibero;

OJS; Revcom

Clase;

Isi Web of

Knowledge $\begin{array}{llll}\text { B3 } 2,0 & 2 & 78,8\end{array}$

B1 $22,0 \quad 80,8$

B2 $2 \quad 2,0 \quad 82,9$

$17 \quad 17,2 \quad 100,0$

Total

$99 \quad 100,0$

Nota: dados do WebQualis 2010

O sinal ... indica dados não disponíveis

Tabela 4: Títulos de Periódicos utilizados para publicação da PI

Fonte: dados da pesquisa

Dentre os periódicos usados para a publicação da produção intelectual, a revista Em

Questão: revista de biblioteconomia e comunicação constitui-se como principal veículo de comunicação da produção docente do DCI (36\%). Este periódico é uma publicação eletrônica da FABICO, criada em 2003 em substituição a Revista de Biblioteconomia e Comunicação e dirige-se a pesquisadores, professores, profissionais e estudantes das áreas de Informação e Comunicação para que possam divulgar resultados inéditos de pesquisas nessas áreas e afins nos idiomas português, espanhol e inglês. Atualmente este periódico está classificado como Qualis B2. Qualis é o conjunto de procedimentos utilizados pela Coordenação de Aperfeiçoamento de Pessoal de Nível Superior (CAPES) ${ }^{3}$ para hierarquizar periódicos científicos (e outros veículos) utilizados por programas de pós-graduação para a divulgação de sua produção intelectual. A estratificação é realizada anualmente e varia de A1 (periódico de excelência na área) até C (peso zero), passando por A2; B1; B2; B3; B4; B5, seguindo critérios adaptados a realidade de cada área específica e levando em conta as discrepâncias entre as subáreas.

\footnotetext{
${ }^{3}$ Informação disponível em: http://www.capes.gov.br/avaliacao/qualis. Acesso em 30 jun. 2011.
} 
Para que um periódico da área da Ciência da Informação possa obter estratificação alta, precisa ser editado por instituição com pós-graduação strictu sensu; deve manter sua periodicidade; precisa ser indexada por pelo menos quatro bases de dados do tipo LISA, ISI, Scopus, Scielo (bases do tipo LATINDEX, REDALYC, DOAJ pontuam também, embora não de maneira tão significativa); deve publicar pelo menos $70 \%$ dos artigos cujos autores tenham vinculo com no mínimo quatro instituições diferentes daquela que edita a publicação; necessita publicar $20 \%$ de artigos de autores filiados a instituições estrangeiras; deve também publicar $80 \%$ de artigos de autores com nível de doutorado.

A porcentagem de publicação no periódico editado pela unidade (36\%) pode não ser interessante para a produtividade do DCI, pois inibe a visibilidade nacional da produção intelectual docente e pode indicar uma tendência ao isolamento científico.

O segundo periódico mais utilizado pelos docentes foi Informação e Sociedade: estudos, revista quadrimestral, criada em 1991 pela Universidade Federal da Paraíba, objetiva divulgar trabalhos que representam contribuição para o desenvolvimento de novos conhecimentos entre pesquisadores, docentes, discentes e profissionais em Ciência da Informação, biblioteconomia e áreas afins, independente de sua vinculação profissional e local de origem. Com uma freqüência menos expressiva como veículos de divulgação da PI, figuram as seguintes revistas: In Texto: Revista do Mestrado da Comunicação da UFRGS, SIGNOS; Revista ACB: biblioteconomia em Santa Catarina, Revista Ciência da Informação, Ecos: Revista da Escola de Comunicação Social.

A análise da colaboração no Departamento de Ciência da Informação da UFRGS evidenciou uma tendência à escrita colaborativa, pois 70,7\% dos trabalhos foram publicados em co-autoria, ao passo que $29,4 \%$ foram publicados individualmente. A autoria dual (assinado por dois autores) constitui-se numa tendência entre os docentes $(35,5 \%)$ e a publicação assinada por mais de três autores não é um hábito entre os mesmos no período analisado.

O estudo revelou o fortalecimento da produção colaborativa no DCI a partir de $2001 \mathrm{e}$, desde então, o aumento de publicações em co-autoria é constante até 2008. A partir destes resultados, objetivou-se investigar a existência de redes de colaboração na produção do DCI/UFRGS. Assim, as relações de colaboração (que estão detalhadas na Tabela 5) das publicações foram examinadas segundo as seguintes categorias não excludentes:

a) Intradepartamental: co-autoria entre docentes vinculados ao DCI (inclui professores substitutos); 
b) Interdepartamental: co-autoria entre docentes do DCI e DECOM (inclui professores substitutos do DECOM);

c) Extra departamental co-autoria entre docentes do DCI e docentes de outros departamentos da UFRGS;

d) Docente Externo: co-autoria entre docentes do DCI e docentes de outras instituições;

e) Alunos de graduação da FABICO: co-autoria entre os professores analisados e alunos de graduação do DCI e DECOM;

f) Outros Alunos de graduação: co-autoria entre os professores analisados e alunos vinculados a cursos de outras unidades;

g) Alunos de Pós-Graduação da FABICO: co-autoria entre os docentes analisados e alunos de pós-graduação do PPGCOM da FABICO;

h) Outros Alunos de Pós-Graduação: co-autoria entre os docentes analisados e alunos de pós-graduação vinculados a outros programas de pós-graduação;

i) OUTROS: engloba a co-autoria entre os docentes analisados com bibliotecários, assessores e outros profissionais (da UFRGS ou de outras instituições).

Como os autores pertencem a diferentes categorias (docentes, alunos de graduação, alunos de pós, etc), uma mesma publicação pode apresentar mais de um tipo de co-autoria. Foram encontradas 222 relações de co-autoria. Em relação a autoria única, esta perfez 73 ocorrências (não apresentadas na tabela 5).

O tipo de relação colaborativa mais frequente nas publicações é a relação Intradepartamental (30,6\%), ou seja, os docentes analisados preferem escrever com colegas do próprio departamento. Um resultado interessante que pode ser observado é a existência de uma endogenia, já que as relações de co-autoria dos professores do DCI com docentes e alunos vinculados à FABICO acumulam 74,3\% das ocorrências.

As relações de colaboração autoral entre professores representaram 48,7\% no total. Em relação à participação discente na autoria, verificou-se uma predominância de alunos de pós-graduação $(24,3 \%)$, explicado pela atuação de alguns professores do DCI no Programa de Pós-Graduação em Comunicação e Informação (PGCOM) durante o período analisado. A categoria outros representa um percentual de 5,4\%, o que talvez signifique que os docentes buscam experiências profissionais para enriquecer suas pesquisas. 
Tipos de co-autoria

Intradepartamental

Alunos pós-graduação FABICO

Alunos graduação FABICO

Interdepartamental

Extra departamental

Outros

Docentes externos

Outros alunos de pós-graduação

Outros alunos de graduação
Freq. Tipos coautoria

68

54

32

11

18

12

11

10

\begin{tabular}{cc}
$\begin{array}{c}\text { \% de Tipos } \\
\text { co-autoria }\end{array}$ & $\begin{array}{c}\sum \% \text { Tipos } \\
\text { co-autoria }\end{array}$ \\
\hline 30,6 & 30,6 \\
24,3 & 54,9 \\
14,4 & 69,3 \\
5,0 & 74,3 \\
8,1 & 82,4 \\
5,4 & 87,8 \\
5,0 & 92,8 \\
4,5 & 97,3 \\
2,7 & $\mathbf{1 0 0}$ \\
\hline $\mathbf{1 0 0 , 0}$ & $\cdot \cdot$
\end{tabular}

\section{TOTAL}

222

100,0

Nota: O sinal " indica que não se aplica dado numérico

Tabela 5:Frequência de Tipos de co-autoria

Fonte: dados da pesquisa

Com base nestas descobertas, houve a necessidade de mapear a organização social dentro do DCI a partir da produção científica produzida em colaboração com o intuito de verificar os principais interesses de publicação dos diferentes núcleos departamentais. Estas redes foram analisadas através dos softwares UCINET e NetDraw. A rede está representada através de um grafo (Figura 1).

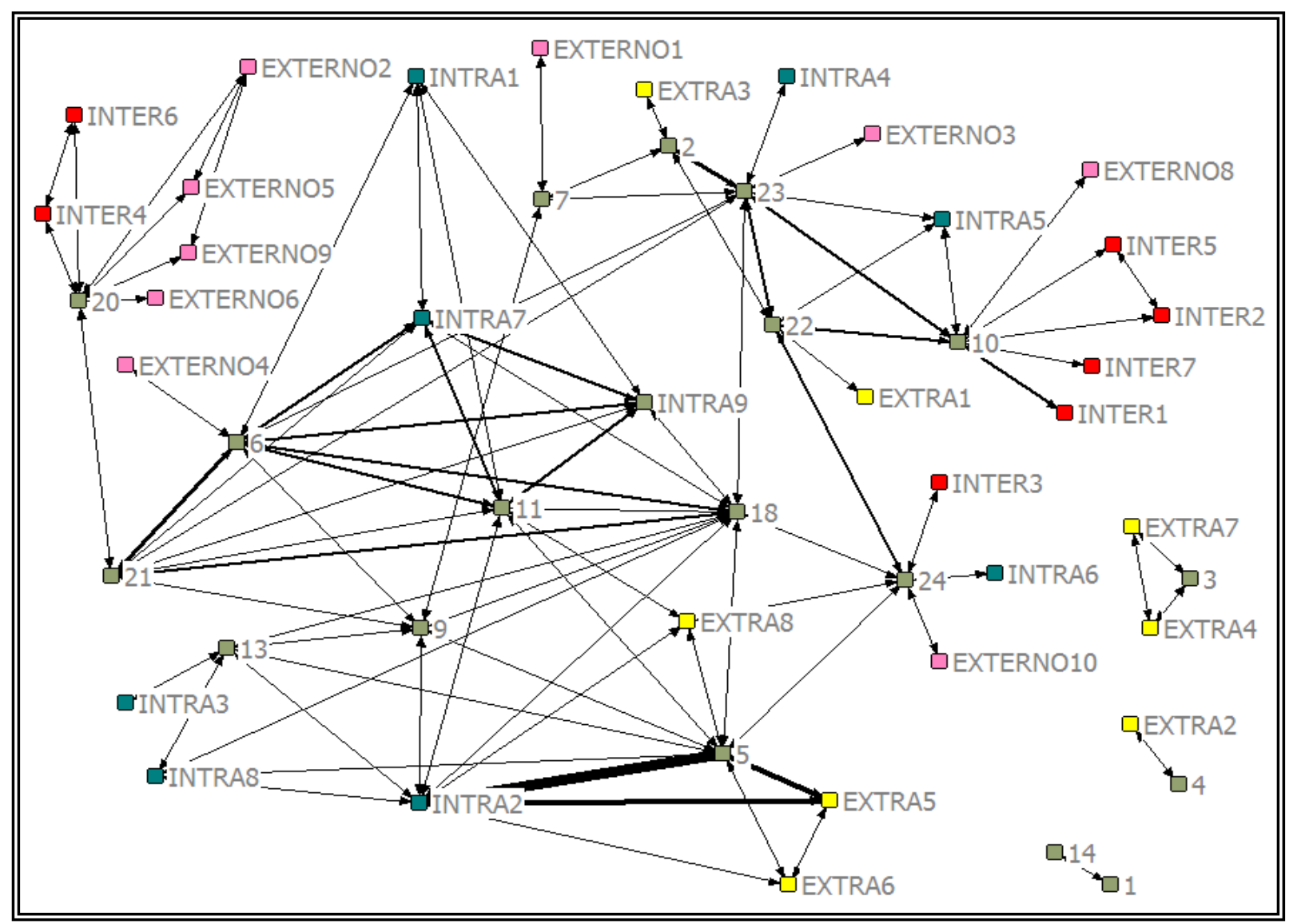

FIGURA 1: Rede de co-autoria dos professores do DCI/UFRGS 
Silva et al. (2006) em estudo das redes de co-autoria dos professores do Programa de Pós-Graduação em Ciência da Informação da UFMG (com base nos trabalhos completos em eventos e artigos de periódicos publicados a partir de 1997, organizados no Sistema CVLattes), concluíram que o estudo da co-autoria configura-se como um dos indicadores da organização social em uma área de pesquisa. Em trabalhos científicos pode ser usado para explicitar os colégios invisíveis. Segundo Silva et al. (2006, p. 180), “a diferença fundamental entre a ARS e outros estudos é que a ênfase não está nos atributos (características) dos atores, mas nas ligações entre os elos; ou seja, a unidade de observação é composta pelo conjunto de atores e seus laços.".

Os professores vinculados ao DCI, analisados neste estudo, tiveram os nomes pessoais omitidos e representados com os números de 1 a 24. Os demais professores estão codificados como INTRA (docentes do DCI, porém sem vínculo permanente: professores substitutos ou já desligados do DCI), INTER (docentes do Departamento de Comunicação da FABICO), EXTRA (docentes de outros departamentos da UFRGS) e EXTERNO (docentes de outras instituições).

Percebe-se na figura que o docente 10, por exemplo, é o que escreve mais com professores do Departamento de Comunicação. Os docentes 3, 4 e 5, por sua vez, preferem colaborar com docentes de outras unidades da UFRGS (Filosofia e Ciências Humanas, Enfermagem e Educação) e o professor 20 apresenta o maior número de colaborações com docentes externos de universidades como a Universidade Federal de Santa Maria e Universidade da Região da Campanha.

Os docentes 3 e 4 estão isolados da rede intradepartamental, ou seja, as áreas de interesse destes professores não se aproximam das áreas de interesse dos demais colegas de departamento. As áreas onde se percebe um emaranhado de linhas representam os professores escrevendo em co-autoria devido à existência de relações indiretas entre eles, ou seja, escrevem esporadicamente sobre temas afins. É o caso dos docentes 9, 11, 13 e 18.

Outro aspecto interessante revelado pela figura é a força com que se estabelecem determinadas relações, linhas mais largas significam maior colaboração, por exemplo, o professor 5 possui muitos trabalhos publicados com INTRA2 (30) e também com EXTRA 5 (13), pois estes atores possuem vínculos de orientador/orientando em nível de pós-graduação.

O estudo das redes de colaboração no PPGCI/UFMG de Silva et al. (2006, p. 11), também apresentou uma concentração dos trabalhos em torno de poucos docentes mais 
produtivos e não reforça a existência de colégios invisíveis na área, pois o tipo de co-autoria encontrado constituiu-se principalmente em intra-institucional.

Maia e Caregnato (2008) afirmam que agências financiadoras de pesquisa estimulam a co-autoria, entre outros motivos, pela economia de tempo e recursos (financeiros e materiais). Em algumas áreas são organizados projetos de cooperação formais para colaboração, mas sabe-se que a colaboração entre duas pessoas é um processo social e de interação humana que pode acontecer de diversas formas e por diferentes motivos, entre eles, os afetivos e também aqueles que dizem respeito a proximidade geográfica e relação de orientador-aluno (VANZ; STUMPF, 2010). Em algumas áreas os colégios invisíveis estabelecem redes de relações informais que bastam para fomentar a colaboração entre os pesquisadores (CRANE, 1972).

Finalmente, a análise dos assuntos (descritores) revelou uma preferência pelos temas Biblioteconomia, Comunicação, Ciência da Informação e Ensino/Aprendizagem, com um percentual acumulado de $25,0 \%$, como pode ser conferido na tabela 6 .

Os assuntos da produção intelectual foram coletados dos termos indexados no SABi de forma a evitar uma dispersão, já que é atribuição do SBU organizar o catálogo de autoridades para assuntos, Apesar disso, os resultados apresentaram dispersão: Biblioteconomia (10,8\%), Bibliotecário (2,2\%), Biblioteca Escolar (1,9\%) e Biblioteca Universitária (1,2\%) são temas afins que representam $16,1 \%$ do assuntos publicados na PI, e da mesma forma, Ensino e Aprendizagem (3,0\%), Ensino a Distância (2,4\%), Ambiente Virtual de Aprendizagem $(0,7 \%)$, Informação na Educação $(0,7 \%)$ e Objeto de Aprendizagem $(0,7 \%)$ representam 7,5\% dos assuntos.

De qualquer forma, as análises dos assuntos publicados são importantes para auxiliar a biblioteca na identificação de inconsistências em seu catálogo de assuntos e também auxiliar em suas política de desenvolvimento de coleções.

\begin{tabular}{lccc}
\hline \multicolumn{1}{c}{ Assunto } & $\begin{array}{c}\text { Freq. } \\
\text { descritores }\end{array}$ & \%descritores & $\sum$ descritores \\
\hline Biblioteconomia & 73 & 10,8 & 10,8 \\
Comunicação & 43 & 6,4 & 17,2 \\
Ciência da Informação & 33 & 4,9 & 22,0 \\
Ensino e Aprendizagem & 20 & 3,0 & 25,0 \\
Tecnologia da Informação & 18 & 2,7 & 27,6 \\
Cidadania & 16 & 2,4 & 30,0 \\
Comunicação Científica & 16 & 2,4 & 32,4 \\
Ensino a Distância & 16 & 2,4 & 34,7 \\
Bibliotecário & 15 & 2,2 & 36,9 \\
Sociologia & 14 & 2,1 & 39,0 \\
Biblioteca Escolar & 13 & 1,9 & 40,9 \\
Pós-Graduação & 11 & 1,6 & 42,6
\end{tabular}


Periódico Científico

$$
10
$$

Análise de Citação

\section{9}

Cultura Popular

Festas Comunitárias

\section{9}

9

Inclusão Digital

Bibliometria

Biblioteca Universitária

Arquivologia

Internet

Recuperação da Informação

Aplicação dos Computadores

Leitura

Periódico Eletrônico

Representação Social

Terminologia

Ambiente Virtual de Aprendizagem

Análise do Discurso

História

Informática na Educação

Literatura

Objetos de Aprendizagem

Produção Científica

140 descritores atribuídos entre 1 e 4 vezes

\section{Total}

Nota: O sinal “ indica que não se aplica dado numérico

Tabela 6:Assuntos da produção intelectual

Fonte: dados da pesquisa

\section{CONSIDERAÇÕES FINAIS}

No âmbito da coordenação das atividades de pesquisas em Ciência da Informação no Brasil, a produção intelectual é utilizada como apoio à tomada de decisões. Presume-se que os resultados alcançados tenham sido consistentes para atender ao objetivo de analisar o Departamento de Ciências da Informação da UFRGS, pois se conseguiu delinear um perfil de publicação e organização social dos professores dentro do DCI, enquanto produtores de conhecimento. Os resultados revelaram uma tendência à escrita colaborativa e à publicação dos trabalhos em canais de comunicação rápida, acessível e subjetivamente atraente, ou seja, anais de eventos e periódicos de circulação nacional. Quando analisado ano a ano, observa-se que a publicação destes tipos de documentos está correlacionada com o aumento da produção intelectual do DCI. Em média, os professores publicaram 27,5 trabalhos por ano, com oscilações entre o mínimo de 9 documentos publicados em 2001 para 42 em 2007. O periódico Em Questão, publicado pela FABICO, foi o principal periódico utilizado como 
canal de comunicação científica, revelando uma tendência ao isolamento científico no departamento. $\mathrm{O}$ idioma predominante nas publicações é a língua portuguesa.

Quanto aos assuntos, temas como Biblioteconomia, Comunicação, Ciência da Informação e Ensino/aprendizagem detém um percentual acumulado de 25,0\% das publicações. Entretanto, detectou-se dispersão nos assuntos indexados pelo Sistema de Bibliotecas da Universidade.

Os resultados da análise de redes de colaboração mostraram que a produção intelectual dos professores do DCI acontece no âmbito da Faculdade: seja em colaboração com os próprios colegas ou com alunos de pós-graduação e graduação. A análise também revelou que poucos professores produtivos agregam colaboradores em seu entorno e estas colaborações favorecem a obtenção de vantagens institucionais (financiamento de projetos, progressões funcionais e alocação de vagas departamentais etc.). Boa parte da organização social ocorre entre autores preferenciais que pesquisam sobre temas afins e esta organização não atrai pesquisadores de diferentes áreas, impedindo o avanço nas discussões interdisciplinares, importantes para o amadurecimento da área de Ciência da Informação. Aparentemente o DCI tem muito a avançar no estabelecimento de suas parcerias.

Vale ressaltar que as políticas de avaliação da ciência brasileira ainda buscam um formato ideal, através de indicadores mais democráticos e condizentes com a nossa realidade, porém, sem se distanciar do padrão internacional. O periódico científico é o principal veículo de comunicação entre cientistas e o impacto ou a visibilidade internacional de um periódico é medido pelo número de vezes que este título é citado pelo conjunto de periódicos da mesma área temática.

Atualmente, os índices bibliográficos que fornecem as medidas de impacto são, internacionalmente, o Journal of Citation Reports (JCR) do ISI (instituição responsável pela compilação dos dados mais completos e significativos para fins de comparações internacionais) e no cenário latino-americano, pela AL\&C e o SciELO. Sendo assim, se torna extremamente importante a oferta de condições e oportunidades para a editoração de periódicos institucionais capazes de atender aos critérios necessários para sua inclusão nestas bases de prestígio, proporcionando aos cientistas brasileiros mais opções para publicar, aumentar sua produção, adquirir status dentro da área de atuação e, consequentemente, contribuir para a consolidação de suas especialidades.

Apesar de seus limites, este trabalho se prestou a contribuir com os conhecimentos já existentes sobre como ocorre o fluxo da comunicação científica na área de Ciência da 
Informação, ainda que o estudo seja restrito a um departamento. A Bibliometria pode ser um método eficiente para investigar a realidade de uma determinada área do conhecimento em diferentes períodos de tempo. Deseja-se que a área conheça a si mesma para a tomada de decisões e mudanças em seus paradigmas, se for o caso.

Os documentos analisados revelaram que a produtividade docente no DCI é baixa no que diz respeito à publicação em periódicos e eventos internacionais, o que por sua vez, revela que ainda há um longo caminho a ser percorrido em busca de inserção no cenário científico internacional. Desta forma, é importante que a coordenação departamental continue incentivando a produção intelectual e estabelecendo metas para ampliar ainda mais a qualidade do que é publicado. Em linhas gerais, no Brasil, a Ciência da Informação ainda é um campo em formação ou construção, sem padrões próprios e consistentes de comportamento em relação aos fluxos de comunicação científica, talvez devido ao seu caráter interdisciplinar com outras ciências sociais. Espera-se também que essa análise contribua para uma avaliação da influência da produção científica do DCI em âmbito nacional.

\section{REFERÊNCIAS}

ARAÚJO, Carlos Alberto. Bibliometria: evolução histórica e questões atuais. Em Questão, Porto Alegre, v. 12, n. 1, p. 11-32, jan./jun. 2006. Disponível em; < http://seer.ufrgs.br/EmQuestao/article/view/16/5>. Acesso em: 02 ago., 2009.

COSTA, Josiane Gonçalves da; VANZ, Samile Andrea de Souza. A Produção intelectual em Ciência da Informação: análise de citações do DCI/UFRGS de 2000 a 2008. Em questão, Porto Alegre, v. 16, n. 1, p. 79-93, jan./jun. 2010.

CRANE, D. Invisible Colleges: diffusion of knowledge in scientific communities. Chicago: The University of Chicago Press, 1972. 213 p.

LE COADIC, Yves-françois. Ciência da Informação. 2. ed. Brasília: Briquet de Lemos, 2004.

MAIA, Maria de Fátima S.; CAREGNATO, Sônia Elisa. Co-autoria como indicador de redes de colaboração científica. Perspectivas em Ciência da Informação, Belo Horizonte, v. 13, n. 2, p. 18-31, maio./ago. 2008. Disponível em; < http://portaldeperiodicos.eci.ufmg.br/index.php/pci/article/viewFile/215/471>. Acesso em: 02 ago. 2009.

MEADOWS, Arthur Jack. A comunicação científica. Brasília: Briquet de Lemos, 1999. 
MUELLER, Suzana Pinheiro Machado; PASSOS, Edilenice Jovelina Lima. Introdução: as questões da comunicação científica e a Ciência da Informação. In: Comunicação Científica. Brasília: DCI/UNB, 2000. p. 13-34.

MUELLER, Suzana Pinheiro Machado. A publicação da ciência: áreas científicas e seus canais preferenciais. DataGramaZero: Revista de Ciência da Informação, Rio de Janeiro, v. 6, n. 1, fev., 2005. Disponível em: <http://www.dgz.org.br/fev05/F_I_aut.htm>. Acesso em: 02 ago. 2009.

SANTOS, Jussara Pereira. FABICO, Fragmentos de uma Trajetória. Revista de Biblioteconomia e Comunicação, Porto Alegre, v. 8, p. 275-299, jan./dez. 2000.

SARACEVIC, Tefko. Ciência da Informação: origem, evolução e relações. Perspectivas em Ciência da Informação, Belo Horizonte, v. 1, n. 1, p. 41-62, jan./jun. 1996. Disponível em: < http://portaldeperiodicos.eci.ufmg.br/index.php/pci/article/view/235/22>. Acesso em: 02 ago. 2009.

SENGUPTA, I. N. Bibliometrics, informetrics, scientometrics and librametrics: an overview. Libri, Munich, v. 42, n. 2, p. 75-98, 1992.

SILVA, Antonio Braz de Oliveira et al. Estudo da rede de co-autoria e da interdisciplinaridade na produção científica com base nos métodos de análise de redes sociais: avaliação do caso do Programa de Pós-graduação em Ciência da Informação - PPGCI/UFMG. Encontros Bibli: Revista Eletrônica de Biblioteconomia e Ciência da Informação, Florianópolis, n. esp., p. 179-194, 2006. Disponível em: $<$ http://www.periodicos.ufsc.br/index.php/eb/article/view/355/422>. Acesso em: 10 mar. 2010 .

SPINAK, Ernesto. Diccionario enciclopédico de bibliometría, cienciometría e informetría. Caracas: Cresalc/Unesco, 1996.

SOUZA, Rosali Fernandez de; STUMPF, Ida Regina Chittó. Ciência da informação como área do conhecimento: abordagem no contexto da pesquisa e da pós-graduação no Brasil. Perspectivas em Ciência da Informação, Belo Horizonte, v. 14, n. esp., p. 51-58, 2009. Disponível em: < http://portaldeperiodicos.eci.ufmg.br/index.php/pci/article/view/901/606>. Acesso em: 10 mar. 2010.

STUMPF, Ida Regina Chitto. Programas de pós-graduação em Ciência da Informação no Brasil: linhas de pesquisa, avaliação e perspectivas. In: COLÓQUIO MEDIAÇÕES E USOS DE SABERES E INFORMAÇÃO: um diálogo França-Brasil, 2008, Rio de Janeiro. Anais... Rio de Janeiro: Rede Mussi, 2008. p.82-98

TAGUE-SUTCLIFFE, J. An introduction to informetrics. Information Processing \& Management, Oxford, v. 28, n. 1, p. 1-3, 1992.

VANTI, Nadia Aurora Peres. Da Bibliometria à webometria: uma exploração conceitual dos mecanismos utilizados para medir o registro da informação e a difusão do conhecimento. Ciência da Informação, Brasília, v. 31. n. 2, p. 152-162, maio/ago. 2002. Disponível em: < http://revista.ibict.br/ciinf/index.php/ciinf/article/view/171/150>. Acesso em: 02 ago. 2009. 
VANZ, Samile Andrea de Souza; CAREGNATO, Sônia Elisa. Estudos de Citação: uma ferramenta para entender a comunicação científica. Em Questão, Porto Alegre, v. 9, n.2, p. 247-259, jul./dez. 2003. Disponível em: < http://seer.ufrgs.br/EmQuestao/article/view/75/35>. Acesso em 10 ago. 2009.

.; STUMPF, Ida Regina Chittó. Colaboração científica: revisão teórico-conceitual. Perspectivas em Ciência da Informação, Belo Horizonte, v. 15, n. 2., p. 42-55, maio/ago, 2010. 18 maio. 2011. 